Anesthesiology Clin 34 (2016) 537-556

\title{
Brain Oxygenation Monitoring
}

Matthew A. Kirkman and Martin Smith*

Neurocritical Care Unit, The National Hospital for Neurology and Neurosurgery,

University College London Hospitals, Queen Square, London, UK.

* Corresponding author email: martin.smith@uclh.nhs.uk

Word Count: $\quad 5601$

Tables: $\quad 5$

Figures: $\quad 1$

Disclosure statement: MS is part funded by the Department of Health National

Institute for Health Research Centres funding scheme via the University College

London Hospitals/University College London Biomedical Research Centre.

Conflicts of interest: None.

Key words: Cerebral oxygenation; cerebral perfusion; brain monitoring; brain tissue oxygen tension; jugular venous saturation; near-infrared spectroscopy. 
Key points:

- The maintenance of adequate cerebral oxygenation is a key goal in the management of patients with acute brain injury and in certain perioperative settings.

- A mismatch between cerebral oxygen supply and demand can lead to cerebral hypoxia/ischemia and deleterious outcomes; cerebral oxygenation monitoring is therefore an important aspect of multimodality neuromonitoring.

- There is abundant evidence of an association between low cerebral oxygenation and outcomes, but limited evidence that increasing cerebral oxygenation improves outcome.

- Advances in cerebral oxygenation monitoring will be driven by improved technology and randomized studies proving the utility of different monitors.

Article synopsis:

A mismatch between cerebral oxygen supply and demand can lead to cerebral hypoxia/ischemia and deleterious outcomes. Cerebral oxygenation monitoring is an important aspect of multimodality neuromonitoring in both the perioperative and intensive care unit settings. It is increasingly deployed whenever ICP monitoring is indicated. Although there is a large body of evidence demonstrating an association between cerebral hypoxia/ischemia and poor outcomes, it remains to be determined whether restoring cerebral oxygenation leads to improved outcomes. Randomized prospective studies are required to address the current uncertainties about cerebral oxygenation monitoring and management. This chapter will describe the different methods of monitoring cerebral oxygenation, their indications, evidence base, limitations and future perspectives. 


\section{INTRODUCTION}

Maintenance of cerebral oxygen supply sufficient to meet demand is a key goal in the management of patients with acute brain injury (ABI), and in perioperative settings. A mismatch between oxygen supply and demand can lead to cerebral hypoxia/ischemia and deleterious outcomes, with time-critical windows to prevent or minimize permanent ischemic neurological injury. The clinical manifestations of cerebral hypoxia/ischemia may remain occult in unconscious or sedated/anesthetized patients, and brain monitoring is required to detect impaired cerebral oxygenation in such circumstances.

Cerebral oxygenation monitoring assesses the balance between cerebral oxygen delivery and utilization, and therefore the adequacy of cerebral perfusion and oxygen delivery. It can be used to guide treatment to prevent or minimize cerebral hypoxia/ischemia, and is established as an important component of multimodality neuromonitoring in both perioperative and intensive care unit (ICU) settings.

This chapter will describe the different methods of bedside cerebral oxygenation monitoring, the indications and evidence base for their use, as well as limitations and future perspectives. 


\section{METHODS OF MONITORING CEREBRAL OXYGENATION}

There exists several imaging and bedside methods of monitoring global and regional cerebral oxygenation, invasively and non-invasively (table 1). Different monitors describe different physiological variables and, for this reason, they are not interchangeable.

Table 1 near here

\section{Imaging techniques}

In addition to providing structural information, several imaging techniques are able to evaluate cerebral hemodynamics and metabolism over multiple regions of interest. Imaging provides only a 'snapshot' of cerebral physiology at a particular moment in time and may miss clinically significant episodes of cerebral hypoxia/ischemia, so continuous, bedside monitoring modalities are preferred during clinical management. The reader is referred elsewhere for a detailed description of the role of imaging after ABI [1].

\section{Jugular venous oxygen saturation monitoring}

Jugular venous oxygen saturation monitoring $\left(\mathrm{SvjO}_{2}\right)$ was the first bedside monitor of cerebral oxygenation, but its' use is being superseded by other monitoring tools.

$\mathrm{SvjO}_{2}$ can be measured through intermittent sampling of blood from a catheter with its tip sited in the jugular venous bulb, or continuously using a fiber-optic catheter. $\mathrm{SvjO}_{2}$ represents a global measure of cerebral oxygenation and provides a nonquantitative estimate of the adequacy of cerebral perfusion based on the simple tenet 
that increased cerebral oxygen demand in the face of inadequate supply increases the proportion of oxygen extracted from hemoglobin and thus reduces the oxygen saturation of blood draining from the brain [2]. The range of normal $\mathrm{SvjO}_{2}$ values is $55 \%$ to $75 \%$, and interpretation of changes is relatively straightforward. Low $\mathrm{SvjO}_{2}$ values may indicate cerebral hypoperfusion secondary to decreased cerebral perfusion pressure (CPP) or hypocapnea, or increased oxygen demand that is not matched by increased supply, whereas high values may indicate relative hyperaemia or arteriovenous shunting. The arterial to jugular venous oxygen content concentration difference, and other derived variables, have been studied extensively as an assessment of CBF [3].

$\mathrm{SjvO}_{2}$ monitoring has been used during cardiac surgery and craniotomy, although its primary role is in the neurointensive care unit where it has been used to detect impaired cerebral perfusion after traumatic brain injury (TBI) and subarachnoid hemorrhage (SAH), to optimize $\mathrm{CPP}$ and, historically, guide therapeutic hyperventilation. However, no interventional trials have confirmed a direct benefit of $\mathrm{SjvO}_{2}$-directed therapy on outcome, and there are several limitations associated with its use (table 1). Importantly, it may miss critical regional ischemia because it is a global, flow-weighted measure. Further, high $\mathrm{SjvO}_{2}$ values are not necessarily reassuring as they may be associated with pathological arteriovenous shunting, and brain death [2].

\section{Brain tissue oxygen tension monitoring}

Recent years have seen an increasing trend towards the direct measurement of brain tissue $\mathrm{PO}_{2}\left(\mathrm{PtiO}_{2}\right)$, particularly in patients in whom ICP monitoring is indicated. 
$\mathrm{PtiO}_{2}$ monitoring has the most robust evidence base of all cerebral oxygenation monitors, and is now considered the 'gold standard' for monitoring cerebral oxygenation at the bedside [4]. It has contributed significantly to our understanding of the pathophysiology of $\mathrm{ABI}$, and emphasized the importance of multimodality neuromonitoring [5].

Evidence from studies of patients with TBI demonstrate that cerebral hypoxia/ischemia can occur when intracranial pressure (ICP) and CPP are within established thresholds for normality [6]. As well as highlighting that ICP and CPP do not directly assess the adequacy of cerebral perfusion, these data suggest that reliance on a single monitoring modality is insufficient to detect cerebral compromise [7].

$\mathrm{PtiO}_{2}$ monitoring has also challenged the role of some components of triple $\mathrm{H}$ therapy in the treatment of SAH [8], such that induced hypertension alone is now preferred in patients with suspected delayed cerebral ischemia (DCI).

\section{Technical aspects}

$\mathrm{PtiO}_{2}$ catheters are similar in size to intraparenchymal ICP monitors and are placed in sub-cortical white matter through single or multiple lumen bolts, via a burr-hole, or at craniotomy. $\mathrm{PtiO}_{2}$ readings are unreliable in the first hour following insertion, and a 'run-in' period is essential. This limits intraoperative applications unless the monitor is already in situ. Correct functioning of the probe is confirmed prior to commencing monitoring through an oxygen challenge, which should be repeated on a daily basis thereafter. A normal probe response is an increase of $200 \%$ or more from baseline $\mathrm{PtiO}_{2}$ following an increase in $\mathrm{FiO}_{2}$ to 1.0 for approximately 20 minutes, although impaired pulmonary function can affect responsiveness. 
$\mathrm{PtiO}_{2}$ is a focal measure; the region of interest interrogated by a $\mathrm{PtiO}_{2}$ probe is approximately $17 \mathrm{~mm}^{2}$. Probe placement is therefore crucial (figure 1), and location in 'at risk' and viable brain tissue is considered optimal by many. Thus, in patients with focal lesions such as intracerebral hemorrhage ( $\mathrm{ICH}$ ) or traumatic contusions, a peri-lesional location is favored, whilst in aneurysmal SAH probe placement in appropriate vascular territories is advised. Such precise placement can be technically challenging or impossible, and risks inadvertent intralesional placement, which does not yield useful information. There is therefore an argument for routine $\mathrm{PtiO}_{2}$ probe placement in 'normal appearing' brain, typically in the non-dominant frontal lobe, when it effectively acts as a global measure of cerebral oxygenation and can guide maintenance of normal physiological function in uninjured brain. This is the preferred site in cases of diffuse brain injury. Satisfactory probe location must always be confirmed with a non-enhanced cranial computed tomography (CT) scan to allow appropriate interpretation of $\mathrm{PtiO}_{2}$ readings. One major caveat of $\mathrm{PtiO}_{2}$ monitoring is that heterogeneity of brain oxygenation, even in 'undamaged' areas of brain, is wellrecognized [9].

Figure 1 near here

\section{Indications for $\mathrm{PtiO}_{2}$ monitoring}

$\mathrm{PtiO}_{2}$ monitoring has been used in both ICU and perioperative settings (table 2), but its primary role, and the one for which there is most evidence, is in the intensive care management of severe TBI $[6,10]$. Recent guidelines from the Neurocritical Care Society recommend that $\mathrm{PtiO}_{2}$ monitoring can be used to titrate individual targets of 
CPP, $\mathrm{PaCO}_{2}, \mathrm{PaO}_{2}$ and hemoglobin concentration, and to manage intracranial hypertension in combination with ICP monitoring [11]. The Brain Trauma Foundation recommends monitoring and managing $\mathrm{PtiO}_{2}$ as a complement to ICP/CPP guided treatment in patients with severe TBI [12]. It has also been used in poor-grade aneurysmal SAH [13], in ICH [14], and has recently been recommended by the Neurocritical Care Society as a mean of detecting DCI in sedated or poor grade SAH patients [15].

Table 2 near here

There have been several published reports of intraoperative $\mathrm{PtiO}_{2}$ monitoring, but no established role for this indication (table 2). However, a patient with an indwelling $\mathrm{PtiO}_{2}$ monitor already in places should have monitoring continued during an operative procedure.

\section{Normal $\mathrm{PtiO}_{2}$ values and thresholds for treatment}

$\mathrm{PtiO}_{2}$ is a complex and dynamic variable representing the interaction between cerebral oxygen delivery and demand [4], as well as tissue oxygen diffusion gradients [16]. Both cerebral and systemic factors influence $\mathrm{PtiO}_{2}$ values (table 3), and $\mathrm{PtiO}_{2}$ is best considered a biomarker of cellular function as opposed to a simple monitor of hypoxia/ischemia. This makes it an appropriate therapeutic target.

Table 3 near here 
Normal brain $\mathrm{PtiO}_{2}$ is reported to lie between 20 and $35 \mathrm{mmHg}(2.66$ and $4.66 \mathrm{kPa}$ ). Positron emission tomography studies of patients with TBI suggest that the ischemic threshold is less than $14 \mathrm{mmHg}(<1.86 \mathrm{kPa})$ [17], and clinical studies indicate that $\mathrm{PtiO}_{2}$ below $10 \mathrm{mmHg}<1.33 \mathrm{kPa}$ ) should be considered an indicator of severe brain hypoxia [9]. However, the threshold for treatment of low $\mathrm{PtiO}_{2}$ remains undecided with recommendations for initiation of treatment varying from $\mathrm{PtiO}_{2} \leq 20 \mathrm{mmHg}(\leq$ $2.66 \mathrm{kPa})$ to $\leq 15 \mathrm{mmHg}(\leq 2 \mathrm{kPa})$. It is important to appreciate that these thresholds have been determined through patient outcomes in relatively small studies rather than pathophysiological evidence of ischemic damage at the cellular level.

Crucial to the interpretation of $\mathrm{PtiO}_{2}$ in the clinical setting is the severity, duration and chronological trend of cerebral hypoxia, and not absolute $\mathrm{PtiO}_{2}$ values in isolation, since it is the overall burden of hypoxia/ischemia that is the key determinant of outcome $[6,9]$. Many uncertainties remain about when and how to treat reduced $\mathrm{PtiO}_{2}$, and this should be the focus of future research efforts. In particular, the efficacy and safety of increasing $\mathrm{FiO}_{2}$ to normalize $\mathrm{PtiO}_{2}$ is uncertain given the (low quality) evidence of a relationship between arterial hyperoxia and increased mortality after ABI [18]. It also remains to be determined whether $\mathrm{PtiO}_{2}$ values above a certain threshold ensure adequate cerebral oxygenation, or whether or how a mildly elevated ICP should be managed in the presence of normal $\mathrm{PtiO}_{2}$ values (see below).

\section{Management of low brain tissue oxygen tension}

There is currently no consensus on how low $\mathrm{PtiO}_{2}$ should be treated. A stepwise approach has been recommended in a manner akin to the treatment of raised ICP, incorporating knowledge of the factors that influence $\mathrm{PtiO}_{2}$ values (figure 1). Exactly 
which intervention, or combination of interventions, is most effective in improving $\mathrm{PtiO}_{2}$ remains unclear. In fact, it appears that it is the responsiveness of the hypoxic brain to a given intervention that is the prognostic factor, with reversal of hypoxia being associated with reduced mortality [19].

Figure 1 near here

\section{Evidence for $\mathrm{PtiO}_{2}$-guided therapy on outcomes}

There is a substantial body of evidence corroborating the relationship between low $\mathrm{PtiO}_{2}$ values and adverse outcomes after TBI and SAH, but relatively little for other conditions. Furthermore, although there is evidence that interventions such as CPP augmentation, normobaric hyperoxia, and red blood cell transfusions can improve low $\mathrm{PtiO}_{2}$ values after $\mathrm{ABI}$, robust evidence that this translates into improved outcomes is lacking. In TBI, most outcome-based studies of $\mathrm{PtiO}_{2}$-guided therapy have compared standard ICP/CPP-guided therapy with $\mathrm{PtiO}_{2}$-guided therapy in association with ICP/CPP-guided therapy, with conflicting findings (table 4). Such variations in reported outcomes may be the result of heterogeneity in study design including different patient populations, different thresholds for intervention and the interventions used to treat low $\mathrm{PtiO}_{2}$, as well as variable study endpoints. Despite difficulties in controlling for these variations, a systematic review of four studies incorporating 491 patients found overall outcome benefits from $\mathrm{PtiO}_{2}$-directed therapy compared to ICP/CPP-guided therapy alone (odds ratio of favorable outcome $=2.1,95 \%$ confidence interval $=1.4-3.1)[10]$. However, all studies included in this systematic review were nonrandomized, and only two (with small sample sizes) were truly prospective. 
Table 4 near here

Preliminary results have recently been released from the prospective, phase II randomized controlled brain tissue oxygen in TBI 2 (BOOST-2) trial, which evaluated the safety and efficacy of $\mathrm{PtiO}_{2}$-directed therapy in 110 adult patients with non-penetrating severe TBI [20]. Participants were randomized to receive either treatment based on ICP monitoring and management alone (target ICP $<20 \mathrm{mmHg}$ ) or treatment based on ICP (same target ICP) and $\mathrm{PtiO}_{2}$ monitoring based on a prespecified protocol to maintain $\mathrm{PtiO}_{2}>20 \mathrm{mmHg}$. The time spent with $\mathrm{PtiO}_{2}<20$ $\mathrm{mmHg}$ was significantly lower in those in the $\mathrm{ICP} / \mathrm{PtiO}_{2}$ group, and there was no difference in adverse events between the two treatment arms. There was a trend towards lower overall mortality and less poor outcome in the $\mathrm{ICP} / \mathrm{PtiO}_{2}$ group, although these differences were not statistically significant $(p=0.229$ and $p=0.221$, respectively) which is unsurprising since this study was not powered for outcome. A larger phase III trial is required to clarify the potential outcome benefits of $\mathrm{PtiO}_{2}-$ guided therapy in TBI, as well as in other brain injury types.

\section{Near-infrared spectroscopy}

Near-infrared (NIR) spectroscopy (NIRS)-derived cerebral oximetry is currently the only non-invasive, bedside monitor of cerebral oxygenation. Commercial devices measure regional cerebral oxygen saturation $\left(\mathrm{rScO}_{2}\right)$ with high temporal and spatial resolution, and permit simultaneous measurement over multiple regions of interest. Despite interest in the clinical application of NIRS for more than three decades, widespread translation into routine clinical practice has not occurred. 


\section{Technical aspects}

Full technical details of the principles NIRS are beyond the scope of this review, and for further information the reader is referred elsewhere [21]. In brief, NIRS systems are based on the transmission and absorption of NIR light (wavelength range $700-$ $950 \mathrm{~nm})$ as it passes through tissue. Several biological molecules, termed chromophores, have distinct absorption spectra in the NIR, and their concentrations can be determined by their relative absorption of light in this wavelength range. From a clinical perspective, oxyhemoglobin $\left(\mathrm{O}_{2} \mathrm{Hb}\right)$ and deoxyhemoglobin $(\mathrm{HHb})$ are the most commonly measured chromophores, although cytochrome $c$ oxidase (CCO), the terminal complex of the electron transfer chain, is increasingly being investigated as a marker of cellular metabolism and may prove clinically more relevant [22]. In adults, NIR light cannot pass across the whole head so the light source and detecting devices are located a few centimeters apart on the same side of the head (reflectance spectroscopy), allowing examination of the superficial cortex.

NIRS interrogates arterial, venous and capillary blood within the field of view, so $\mathrm{rScO}_{2}$ values represent a weighted tissue oxygen saturation measured from these three compartments. $\mathrm{rScO}_{2}$ values are also influenced by several physiological variables including arterial oxygen saturation, $\mathrm{PaCO}_{2}$, systemic blood pressure, hematocrit, cerebral blood flow $(\mathrm{CBF})$, cerebral blood volume (CBV), cerebral metabolic rate $\left(\mathrm{CMRO}_{2}\right)$ and cerebral arterial:venous (a:v) ratio [21].

Most commercial devices use spatially resolved spectroscopy to derive a scaled absolute hemoglobin concentration representing the relative proportions of oxy- and 
deoxyhemoglobin within the field of view, from which $\mathrm{rScO}_{2}$ is calculated and displayed as a percentage value. Frequency (or domain) resolved spectroscopy and time resolved spectroscopy (TRS) allow measurement of absolute chromophore concentration with obvious advantages [23]. More recently, diffuse correlation spectroscopy techniques have been developed to monitor $\mathrm{CBF}$ and derive $\mathrm{CMRO}_{2}$ $[24,25]$.

There are several concerns over the clinical application of NIRS, particularly 'contamination' of the signal by extracranial tissue. Some commercial cerebral oximeters use two detectors and a subtraction based algorithm to deal with this problem, assuming that the detector closest to the emitter receives light that has passed mainly through the scalp, and that the farthest light has passed mainly through brain tissue. Although there is weighting in favor of intracerebral tissue with an emitter-detector spacing greater than $4 \mathrm{~cm}$, even spatially resolved spectroscopy is prone to some degree of extracerebral contamination [26], and this will be particularly problematic during low CBF states. The NIRS-derived CCO signal is highly specific for intracerebral changes, potentially making it a superior biomarker to hemoglobinbased NIRS variables [27].

\section{Indications}

There are many FDA-approved NIRS devices available for clinical use. Because the specific algorithms incorporated into commercial devices vary, and are often unpublished, it is difficult to compare $\mathrm{rScO}_{2}$ values between devices and therefore between studies using different devices. There are very limited numbers of highquality clinical studies to guide the clinical use of NIRS, and prospective randomized 
studies are required not only to establish its potential role in patient monitoring but also to assess the relative efficacy of the multitude of devices on the market [28].

Recent years have seen a significant increase in the use of perioperative cerebral oximetry (table 2), particularly during cardiac and carotid surgery, and surgery in the head-up (beach chair) position [21]. Although secondary ischemic injury following $\mathrm{ABI}$ is common, and low $\mathrm{rScO}_{2}$ values have been associated with poor outcome in case series, data on the use of NIRS in the ICU management of ABI are limited and no outcome studies of NIRS-guided treatment have been published.

There are emerging applications for NIRS as a non-invasive monitor of cerebral autoregulation, using standard signal processing techniques [29] and also novel analytical techniques of multimodal monitoring of slow wave oscillations [30]. NIRS has also been used to determine optimal CPP non-invasively in patients with TBI [31]. Because of the key role of $\mathrm{CCO}$ in mitochondrial metabolism, monitoring CCO concentration in addition to oxygenation variables may aid in the determination of ischemic thresholds following ABI by providing additional information about cellular metabolic failure [22].

One challenge in the application of NIRS after ABI is that the presence of intracranial hematoma, cerebral edema or subarachnoid blood may invalidate some of the assumptions upon which NIRS algorithms are based [21]. This has been used to advantage in the identification of intracranial hematomas and cerebral edema [32, 33].

Normal $\mathrm{rScO}_{2}$ values and thresholds for treatment 
The 'normal' range of $\mathrm{rScO}_{2}$ is usually reported to lie between $60 \%$ and $75 \%$, but there is substantial intra- and inter-individual variability; NIRS-based cerebral oximetry is therefore best considered as a trend monitor. There are no validated $\mathrm{rScO}_{2}$-derived ischemic thresholds [21] but clinical studies and management protocols often use absolute $\mathrm{rScO}_{2}$ values of $\leq 50 \%$, or $\mathrm{a} \geq 20 \%$ reduction from baseline, as triggers for initiating measures to improve cerebral oxygenation.

\section{Evidence of NIRS-guided therapy on outcomes}

The only evidence for outcome effects of NIRS-guided treatment is from three randomized controlled trials in patients undergoing cardiac surgery [34-36] (table 5). In small studies, intraoperative cerebral oxygen desaturation has been associated with early and late cognitive decline after cardiac surgery, but a recent systematic review concluded that only low-level evidence links intraoperative desaturation with postoperative neurologic complications [37]. There is also insufficient evidence to conclude that interventions to prevent or treat reductions in $\mathrm{rScO}_{2}$ are effective in preventing stroke or postoperative cognitive dysfunction after cardiac surgery. Interestingly, NIRS-guided therapy may improve overall organ outcome after cardiac surgery, suggesting a role for NIRS as a monitor of overall organ perfusion [34]. A systematic review of the role of $\mathrm{rScO}_{2}$ in pediatric patients undergoing surgery for congenital heart disease also concluded that there is no evidence that $\mathrm{rScO} 2$ monitoring and management leads to a clinical improvement in short-term neurologic outcome in this patient population [38].

Table 5 near here 
Several methods are used to assess the adequacy of CBF and oxygen delivery during carotid surgery to inform the critical decision regarding shunt placement during the vessel cross-clamp period. Cerebral oximetry has similar accuracy for the detection of cerebral ischemia compared to other commonly used monitoring modalities, and advantages in terms of simplicity [39]. Various thresholds have been used to determine the need for shunt placement, ranging from a $10 \%$ to $20 \%$ reduction in ipsilateral $\mathrm{rScO}_{2}$ from baseline [40]. Cerebral oximetry has higher temporal and spatial resolution compared to other modalities, and may thus find a role in guiding the manipulation of systemic physiology to minimize the risk of cerebral hypoxia/ischemia during carotid surgery [21]. Recently, the use of a time-resolved optical imaging system which allows simultaneous acquisition of data from 32 regions of interest over both hemispheres has been described [41]. Distinct patterns of changes in $\mathrm{Hb}$ and $\mathrm{O}_{2} \mathrm{Hb}$ were observed in ipsilateral brain cortex, suggesting that non-invasive optical imaging of brain tissue hemodynamics may find a role during carotid surgery.

There has been intense interest in the application of cerebral oximetry in patients undergoing surgery in the beach chair position because of the risk of hypotensionrelated cerebral ischemic events in anesthetized patients in the steep head-up position. In a recent study of 50 patients undergoing shoulder surgery in the beach chair position, the incidence of intraoperative cerebral desaturation events (defined as decreases in $\mathrm{rScO}_{2}$ of $\geq 20 \%$ from baseline) was $18 \%$ [42]. Of those experiencing desaturation, the mean maximal decrease in $\mathrm{rScO}_{2}$ was $32 \%$ from preoperative baseline, and the mean number of separate desaturation events was 1.89 with an average duration of more than 3 minutes. Despite this apparently alarming high 
burden of cerebral desaturation, these and other authors have not identified an association between desaturation events and postoperative neurocognitive dysfunction in this patient population. It has been suggested that changes in intracranial geometry and cerebral a:v ratio related to movement from supine to upright position might account, at least in part, for the changes in measured cerebral saturations [23].

Finally, there is no evidence that monitoring and early detection of cerebral desaturations to guide targeted interventions improves perioperative outcomes during other surgical procedures under general anesthesia [40].

\section{Future perspectives}

Technological developments are likely to be key drivers in advancing cerebral oxygenation monitoring and its adoption in the ICU and perioperative settings. A multiparameter probe that combines ICP, $\mathrm{PtiO}_{2}$, and temperature measurements is available commercially (Raumedic AG, Munchberg, Germany), allowing multimodality monitoring via a single invasive device. The addition of $\mathrm{CBF}$ quantification into such a probe is likely. Advances in $\mathrm{PtiO}_{2}$ technology should allow for improved insertion techniques and more durable devices, and stereotactic placement of invasive probes may help target regions of interest with improved accuracy.

Cerebral arterial oxygen saturation has been estimated using fiber optic pulse oximetry [43], and a prototype invasive probe that combines NIRS and indocyanine green dye dilution has been investigated for the simultaneous monitoring of ICP, CBF, and CBV, avoiding NIRS signal contamination by extracerebral tissues [44]. 
Combined NIRS/EEG provides a unique opportunity to acquire, non-invasively and simultaneously, regional cerebral electrophysiological and hemodynamic data to elucidate on neurovascular coupling mechanisms [45]. A prototype device combining diffuse correlation spectroscopy and NIRS for the bedside measurement of CBF and cerebral oxygenation respectively has been described [46]. In the future, a single NIRS-based device may be able to provide non-invasive monitoring of cerebral oxygenation, hemodynamics and cellular metabolic status over multiple regions of interest, although substantial technological advances are necessary before any of these techniques can be introduced into routine clinical practice.

\section{Conclusions}

Cerebral oxygenation represents the balance between cerebral oxygen supply and demand, and a mismatch may lead to cerebral hypoxia/ischemia with deleterious outcomes. There are several tools available for the detection of cerebral hypoxia/ischemia, each with inherent advantages and disadvantages. Although there is a large body of evidence supporting an association between cerebral hypoxia/ischemia and poor outcomes, it remains to be determined whether restoring cerebral oxygenation improves outcomes. The adoption of a multi-modality neuromonitoring approach (see also chapter 7) that incorporates cerebral oxygenation monitoring in addition to more established ICP and CPP monitoring is required, along with large randomized prospective studies to address the current uncertainties about such approaches. 


\section{References}

1. Duckworth JL, Stevens RD (2010) Imaging brain trauma. Curr Opin Crit Care 16:92-97.

2. Schell RM, Cole DJ (2000) Cerebral monitoring: jugular venous oximetry. Anesth Analg 90:559-566.

3. Macmillan CS, Andrews PJ (2000) Cerebrovenous oxygen saturation monitoring: practical considerations and clinical relevance. Intensive Care Med 26:1028-1036.

4. Rose JC, Neill TA, Hemphill JC (2006) Continuous monitoring of the microcirculation in neurocritical care: an update on brain tissue oxygenation. Curr Opin Crit Care 12:97-102.

5. Bouzat P, Sala N, Payen J-F, Oddo M (2013) Beyond intracranial pressure: optimization of cerebral blood flow, oxygen, and substrate delivery after traumatic brain injury. Ann Intensive Care 3:23.

6. Oddo M, Levine JM, Mackenzie L, et al. (2011) Brain hypoxia is associated with short-term outcome after severe traumatic brain injury independently of intracranial hypertension and low cerebral perfusion pressure. Neurosurgery 69:1037-1045.

7. Kirkman MA, Smith M (2014) Intracranial pressure monitoring, cerebral perfusion pressure estimation, and ICP/CPP-guided therapy: a standard of care or optional extra after brain injury? Br J Anaesth 112:35-46.

8. Muench E, Horn P, Bauhuf C, et al. (2007) Effects of hypervolemia and hypertension on regional cerebral blood flow, intracranial pressure, and brain tissue oxygenation after subarachnoid hemorrhage. Crit Care Med 35:18441851.

9. van den Brink WA, van Santbrink H, Steyerberg EW, et al. (2000) Brain oxygen tension in severe head injury. Neurosurgery 46:868-876.

10. Nangunoori R, Maloney-Wilensky E, Stiefel M, et al. (2012) Brain Tissue Oxygen-Based Therapy and Outcome After Severe Traumatic Brain Injury: A Systematic Literature Review. Neurocrit Care 17:131-138.

11. Oddo M, Bösel J, and the Participants in the International Multidisciplinary Consensus Conference on Multimodality Monitoring (2014) Monitoring of Brain and Systemic Oxygenation in Neurocritical Care Patients. Neurocrit Care 21:103-120.

12. Brain Trauma Foundation, (2007) Guidelines for the management of severe traumatic brain injury. J Neurotrauma 24 Suppl 1:S1-106.

13. Jaeger M, Schuhmann MU, Soehle M, et al. (2007) Continuous monitoring of cerebrovascular autoregulation after subarachnoid hemorrhage by brain tissue oxygen pressure reactivity and its relation to delayed cerebral infarction. Stroke 
38:981-986.

14. Kirkman MA, Smith M (2013) Supratentorial intracerebral hemorrhage: a review of the underlying pathophysiology and its relevance for multimodality neuromonitoring in neurointensive care. J Neurosurg Anesthesiol 25:228-239.

15. Diringer MN, Bleck TP, Claude Hemphill J, et al. (2011) Critical care management of patients following aneurysmal subarachnoid hemorrhage: recommendations from the Neurocritical Care Society's Multidisciplinary Consensus Conference. Neurocrit Care 15: 211-240.

16. Rosenthal G, Hemphill JC, Sorani M, et al. (2008) Brain tissue oxygen tension is more indicative of oxygen diffusion than oxygen delivery and metabolism in patients with traumatic brain injury. Crit Care Med 36:1917-1924.

17. Johnston AJ, Steiner LA, Coles JP, et al. (2005) Effect of cerebral perfusion pressure augmentation on regional oxygenation and metabolism after head injury. Crit Care Med 33:189-195.

18. Damiani E, Adrario E, Girardis M, et al. (2014) Arterial hypoxia and mortality in critically ill patients: a systematic review and meta-analysis. Critical Care 18:711.

19. Bohman L-E, Pisapia JM, Sanborn MR, et al. (2013) Response of Brain Oxygen to Therapy Correlates with Long-Term Outcome After Subarachnoid Hemorrhage. Neurocrit Care 19:320-328.

20. Shutter L BOOST 2 Trial Study Results. Annual Neurocritical Care Society Meeting. (Online - available at: http://www.neurocriticalcare.org/news/2014annual-meeting-highlights [last accessed on October 13, 2015]).

21. Ghosh A, Elwell C, Smith M (2012) Review article: cerebral near-infrared spectroscopy in adults: a work in progress. Anesth Analg 115:1373-1383.

22. Smith M, Elwell C (2009) Near-infrared spectroscopy: shedding light on the injured brain. Anesth Analg 108:1055-1057.

23. Smith M (2011) Shedding light on the adult brain: a review of the clinical applications of near-infrared spectroscopy. Philosophical Transactions of the Royal Society A: Mathematical, Physical and Engineering Sciences 369:44524469.

24. Diop M, Verdecchia K, Lee TY, St Lawrence K (2011) Calibration of diffuse correlation spectroscopy with a time-resolved near-infrared technique to yield absolute cerebral blood flow measurements. Biomed Opt Express 2:20682081.

25. Verdecchia K, Diop M, Lee T-Y, St Lawrence K (2013) Quantifying the cerebral metabolic rate of oxygen by combining diffuse correlation spectroscopy and time-resolved near-infrared spectroscopy. J Biomed Opt 18:27007-027007. 
26. Davie SN, Grocott HP (2012) Impact of extracranial contamination on regional cerebral oxygen saturation: a comparison of three cerebral oximetry technologies. Anesthesiology 116:834-840.

27. Kolyva C, Ghosh A, Tachtsidis I, et al. (2014) Cytochrome c oxidase response to changes in cerebral oxygen delivery in the adult brain shows higher brainspecificity than haemoglobin. Neuroimage 85 Pt 1:234-244.

28. Douds M, Straub E, Kent A, et al. (2014) A systematic review of cerebral oxygenation-monitoring devices in cardiac surgery. Perfusion.

29. Zweifel C, Castellani G, Czosnyka M, et al. (2010) Noninvasive monitoring of cerebrovascular reactivity with near infrared spectroscopy in head-injured patients. J Neurotrauma 27:1951-1958.

30. Highton D, Ghosh A, Tachtsidis I, et al. (2015) Monitoring cerebral autoregulation after brain injury: multimodal assessment of cerebral slow-wave oscillations using near-infrared spectroscopy. Anesth Analg 121:198-205.

31. Dias C, Silva MJ, Pereira E, et al. (2015) Optimal Cerebral Perfusion Pressure Management at Bedside: A Single-Center Pilot Study. Neurocrit Care 23:92102.

32. Gopinath SP, Robertson CS, Contant CF, et al. (1995) Early detection of delayed traumatic intracranial hematomas using near-infrared spectroscopy. Journal of Neurosurgery 83:438-444.

33. Damian MS, Schlosser R (2007) Bilateral near infrared spectroscopy in spaceoccupying middle cerebral artery stroke. Neurocrit Care 6:165-173.

34. Murkin JM, Adams SJ, Novick RJ, et al. (2007) Monitoring brain oxygen saturation during coronary bypass surgery: a randomized, prospective study. Anesth Analg 104:51-58.

35. Slater JP, Guarino T, Stack J, et al. (2009) Cerebral oxygen desaturation predicts cognitive decline and longer hospital stay after cardiac surgery. Ann Thorac Surg 87:36-44-discussion 44-5.

36. Deschamps A, Lambert J, Couture P, et al. (2013) Reversal of decreases in cerebral saturation in high-risk cardiac surgery. Journal of Cardiothoracic and Vascular Anesthesia 27:1260-1266.

37. Zheng F, Sheinberg R, Yee M-S, et al. (2013) Cerebral near-infrared spectroscopy monitoring and neurologic outcomes in adult cardiac surgery patients: a systematic review. Anesth Analg 116:663-676.

38. Hirsch JC, Charpie JR, Ohye RG, Gurney JG (2009) Near-infrared spectroscopy: what we know and what we need to know--a systematic review of the congenital heart disease literature. J Thorac Cardiovasc Surg 137:154-9$159 \mathrm{e} 1-12$.

39. Moritz S, Kasprzak P, Arlt M, et al. (2007) Accuracy of cerebral monitoring in 
detecting cerebral ischemia during carotid endarterectomy: a comparison of transcranial Doppler sonography, near-infrared spectroscopy, stump pressure, and somatosensory evoked potentials. Anesthesiology 107:563-569.

40. Nielsen HB (2014) Systematic review of near-infrared spectroscopy determined cerebral oxygenation during non-cardiac surgery. Front Physiol 5:93.

41. Kacprzak M, Liebert A, Staszkiewicz W, et al. (2012) Application of a timeresolved optical brain imager for monitoring cerebral oxygenation during carotid surgery. J Biomed Opt 17:016002-01600210.

42. Salazar D, Sears BW, Andre J, et al. (2013) Cerebral desaturation during shoulder arthroscopy: a prospective observational study. Clin Orthop Relat Res 471:4027-4034.

43. Phillips JP, Langford RM, Chang SH, et al. (2010) Cerebral arterial oxygen saturation measurements using a fiber-optic pulse oximeter. Neurocrit Care 13:278-285.

44. Keller E, Froehlich J, Muroi C, et al. (2011) Neuromonitoring in intensive care: a new brain tissue probe for combined monitoring of intracranial pressure (ICP) cerebral blood flow (CBF) and oxygenation. Acta Neurochir Suppl 110:217-220.

45. Cooper RJ, Hebden JC, O'Reilly H, et al. (2011) Transient haemodynamic events in neurologically compromised infants: a simultaneous EEG and diffuse optical imaging study. Neuroimage 55:1610-1616.

46. Kim MN, Durduran T, Frangos S, et al. (2010) Noninvasive measurement of cerebral blood flow and blood oxygenation using near-infrared and diffuse correlation spectroscopies in critically brain-injured adults. Neurocrit Care 12:173-180.

47. Eriksson EA, Barletta JF, Figueroa BE, et al. (2012) The first 72 hours of brain tissue oxygenation predicts patient survival with traumatic brain injury. $\mathrm{J}$ Trauma Acute Care Surg 72:1345-1349.

48. Meixensberger J, Renner C, Simanowski R, et al. (2004) Influence of cerebral oxygenation following severe head injury on neuropsychological testing. Neurol Res 26:414-417.

49. Radolovich DK, Czosnyka M, Timofeev I, et al. (2010) Transient changes in brain tissue oxygen in response to modifications of cerebral perfusion pressure: an observational study. Anesth Analg 110:165-173.

50. Bohman L-E, Heuer GG, Macyszyn L, et al. (2011) Medical Management of Compromised Brain Oxygen in Patients with Severe Traumatic Brain Injury. Neurocrit Care 14:361-369.

51. Ramakrishna R, Stiefel M, Udoetuk J, et al. (2008) Brain oxygen tension and outcome in patients with aneurysmal subarachnoid hemorrhage. Journal of 
Neurosurgery 109:1075-1082.

52. Jaeger M, Soehle M, Schuhmann MU, Meixensberger J (2012) Clinical significance of impaired cerebrovascular autoregulation after severe aneurysmal subarachnoid hemorrhage. Stroke 43:2097-2101.

53. Ko S-B, Choi HA, Parikh G, et al. (2011) Multimodality monitoring for cerebral perfusion pressure optimization in comatose patients with intracerebral hemorrhage. Stroke 42:3087-3092.

54. Dohmen C, Bosche B, Graf R, et al. (2007) Identification and clinical impact of impaired cerebrovascular autoregulation in patients with malignant middle cerebral artery infarction. Stroke 38:56-61.

55. Carvi y Nievas M, Toktamis S, Höllerhage H-G, Haas E (2005) Hyperacute measurement of brain-tissue oxygen, carbon dioxide, $\mathrm{pH}$, and intracranial pressure before, during, and after cerebral angiography in patients with aneurysmatic subarachnoid hemorrhage in poor condition. Surg Neurol 64:362-367.

56. Jödicke A, Hübner F, Böker D-K (2003) Monitoring of brain tissue oxygenation during aneurysm surgery: prediction of procedure-related ischemic events. Journal of Neurosurgery 98:515-523.

57. Ibanez J, Vilalta A, Mena MP, et al. (2003) Intraoperative detection of ischemic brain hypoxia using oxygen tissue pessure microprobes (in Spanish). Neurocirugia (Astur) 14:483-489.

58. Dunham CM, Ransom KJ, Flowers LL, et al. (2004) Cerebral hypoxia in severely brain-injured patients is associated with admission Glasgow Coma Scale score, computed tomographic severity, cerebral perfusion pressure, and survival. J Trauma 56:482-9- discussion 489-91.

59. Yokose N, Sakatani K, Murata Y, et al. (2010) Bedside monitoring of cerebral blood oxygenation and hemodynamics after aneurysmal subarachnoid hemorrhage by quantitative time-resolved near-infrared spectroscopy. World Neurosurg 73:508-513.

60. Hametner C, Stanarcevic P, Stampfl S, et al. (2015) Noninvasive cerebral oximetry during endovascular therapy for acute ischemic stroke: an observational study. J Cereb Blood Flow Metab.

61. Laflam A, Joshi B, Brady K, et al. (2015) Shoulder surgery in the beach chair position is associated with diminished cerebral autoregulation but no differences in postoperative cognition or brain injury biomarker levels compared with supine positioning: the anesthesia patient safety foundation beach chair study. Anesth Analg 120:176-185.

62. Adamides AA, Cooper DJ, Rosenfeldt FL, et al. (2009) Focal cerebral oxygenation and neurological outcome with or without brain tissue oxygenguided therapy in patients with traumatic brain injury. Acta Neurochir (Wien) 151:1399-1409. 
63. Meixensberger J, Jaeger M, Vath A, et al. (2003) Brain tissue oxygen guided treatment supplementing ICP/CPP therapy after traumatic brain injury. J Neurol Neurosurg Psychiatry 74:760-764.

64. Stiefel MF, Spiotta A, Gracias VH, et al. (2005) Reduced mortality rate in patients with severe traumatic brain injury treated with brain tissue oxygen monitoring. Journal of Neurosurgery 103:805-811.

65. Martini RP, Deem S, Yanez ND, et al. (2009) Management guided by brain tissue oxygen monitoring and outcome following severe traumatic brain injury. J Neurosurg 111:644-649.

66. McCarthy MC, Moncrief H, Sands JM, et al. (2009) Neurologic outcomes with cerebral oxygen monitoring in traumatic brain injury. Surgery 146:585-590.

67. Narotam PK, Morrison JF, Nathoo N (2009) Brain tissue oxygen monitoring in traumatic brain injury and major trauma: outcome analysis of a brain tissue oxygen-directed therapy. J Neurosurg 111:672-682.

68. Spiotta AM, Stiefel MF, Gracias VH, et al. (2010) Brain tissue oxygen-directed management and outcome in patients with severe traumatic brain injury. $\mathrm{J}$ Neurosurg 113:571-580.

69. Green JA, Pellegrini DC, Vanderkolk WE, et al. (2013) Goal Directed Brain Tissue Oxygen Monitoring Versus Conventional Management in Traumatic Brain Injury: An Analysis of In Hospital Recovery. Neurocrit Care 18:20-25. 


\section{Figure 1}

Schematic for the management of low $\mathrm{PtiO}_{2}$ values

$C P P$, cerebral perfusion pressure; EEG, electroencephalography; $\mathrm{ETCO}_{2}$, end-tidal carbon dioxide; $\mathrm{FiO}_{2}$, fraction of inspired oxygen; ICP, intracranial pressure; MAP, mean arterial pressure; $\mathrm{PaCO}_{2}$, arterial partial pressure of carbon dioxide; $\mathrm{PaO}_{2}$, arterial partial pressure of oxygen; PEEP, positive end-expiratory pressure; $\mathrm{PtiO}_{2}$, brain tissue oxygen tension.

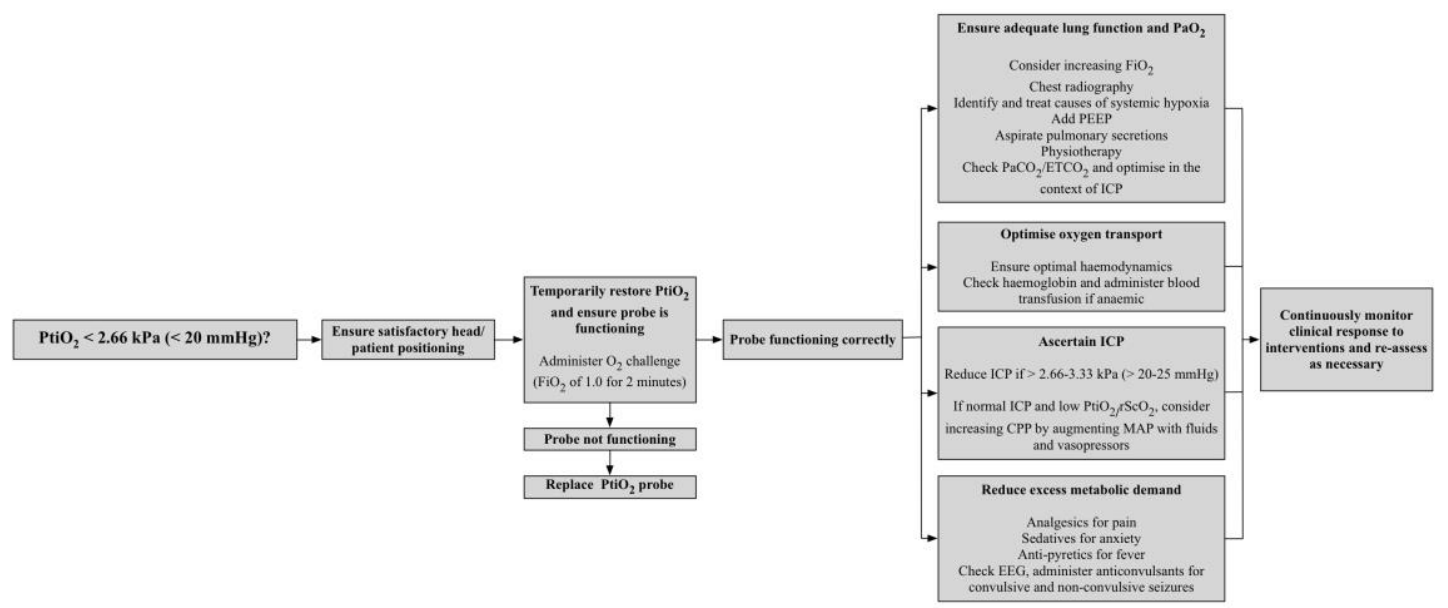


Figure 2

Axial computed tomography scan of the head demonstrating positioning of a $\mathrm{PtiO}_{2}$ probe (arrow):

A. in normal appearing white matter of the right frontal lobe to measure global cerebral oxygenation;

B. suboptimally within a contusion;

C. adjacent to a penumbral region to monitor cerebral oxygenation in 'at risk' tissue.

(Reproduced with permission of Elsevier from Le Roux and Oddo. Neurosurg Clin N Am 2013; 24: 427-39).
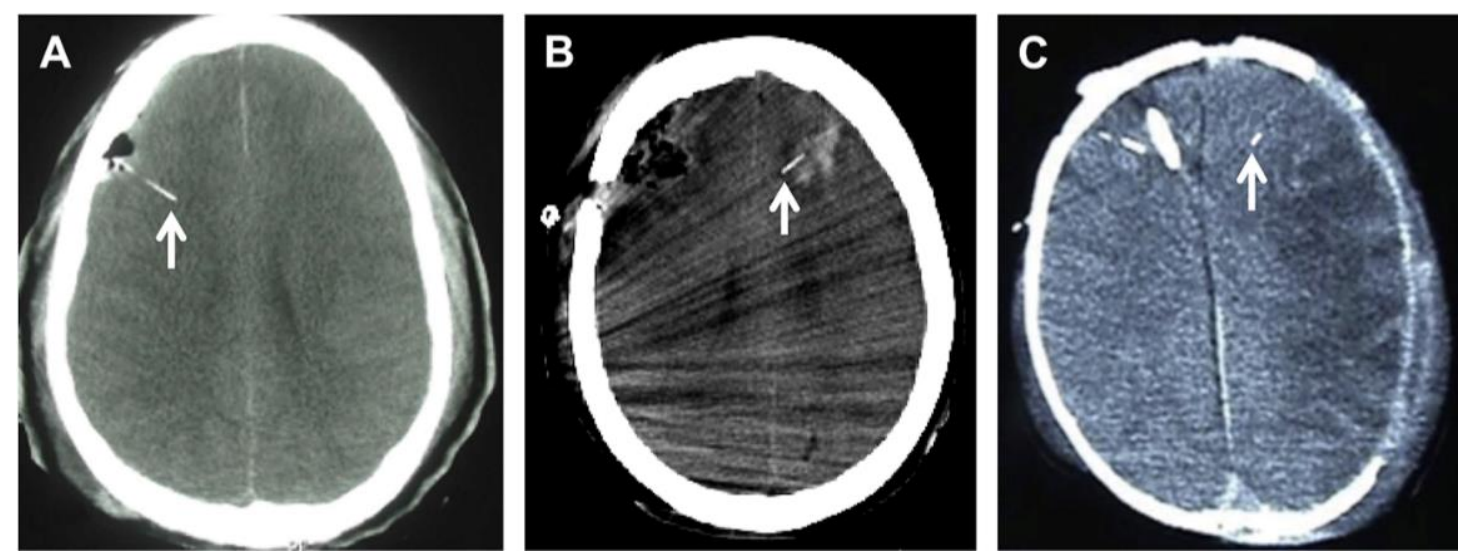


\section{Table 1}

Bedside monitors of cerebral oxygenation

\begin{tabular}{|c|c|}
\hline & Advantages \\
\hline $\mathrm{SjvO}_{2}$ & $\begin{array}{l}\text { - Real-time } \\
\text { - Global trend monitor }\end{array}$ \\
\hline $\mathrm{PtiO}_{2}$ & $\begin{array}{l}\text { - Focal monitor permitting selective monitoring of critically } \\
\text { - Rerfused tissue } \\
\text { - Real-time } \\
\text { - The most effective bedside method of detecting cerebral } \\
\text { - Relatively safe with low hematoma rate }(<2 \% \text {, usually small } \\
\text { and clinically insignificant }) \\
\text { - No reported infections }\end{array}$ \\
\hline NIRS & $\begin{array}{l}\text { - Real-time } \\
\text { - High spatial and temporal resolution } \\
\text { - Non-invasive }\end{array}$ \\
\hline
\end{tabular}

Disadvantages

- Invasive insertion procedure with risk of hematoma, carotid puncture and vein thrombosis during prolonged monitoring

- Insensitive to regional ischemia

- Assumes stable $\mathrm{CMRO}_{2}$ to infer $\mathrm{CBF}$ changes

- Focal monitor -the position of the probe is crucial

- May miss important pathology distant from the monitored site

- Invasive

- Small degree of zero and sensitivity drift

- One hour 'run-in' period required and thus critical early hypoxic/ischemic episodes may go undetected

- Technical complication rates (dislocation or drift) may reach $13.6 \%$

- Extracerebral circulation may 'contaminate' cerebral oxygenation measurements

- Lack of standardization between commercial devices

- 'Thresholds' for cerebral hypoxia/ischemia undetermined

- Current devices only monitor relative changes in oxygenation

$C B F$, cerebral blood flow; $\mathrm{CMRO}_{2}$, cerebral metabolic rate for oxygen, $C P P$, cerebral perfusion pressure; ICP, intracranial pressure; NIRS, near infrared spectroscopy; $\mathrm{PtiO}_{2}$, brain tissue oxygen tension; $\mathrm{Sjv}_{2}$, jugular venous oxygen saturation. 


\section{Table 2}

The main indications for $\mathrm{PtiO}_{2}$ monitoring and NIRS in the perioperative and intensive care settings, based upon clinical data

\begin{tabular}{|c|c|c|c|}
\hline Modality & Indications & Evidence & Highest quality evidence \\
\hline \multirow[t]{10}{*}{$\mathrm{PtiO}_{2}$} & ICU: & & \\
\hline & Severe TBI & $\begin{array}{l}\text { Low } \mathrm{PtiO}_{2} \text { associated with worse mortality [47], lower GOS [6, 9], } \\
\text { and increased neuropsychological deficits [48] }\end{array}$ & Prospective observational \\
\hline & & Treatment of low $\mathrm{PtiO}_{2}$ may improve outcomes $[10,20]$ & Randomized controlled trial \\
\hline & & $\mathrm{PtiO}_{2}$ can help define individual CPP thresholds [49] & Prospective observational \\
\hline & & $\begin{array}{l}\text { Response to } \mathrm{PtiO}_{2} \text { guided therapy associated with reduced mortality } \\
{[50]}\end{array}$ & $\begin{array}{l}\text { Retrospective analysis of } \\
\text { prospective observational data }\end{array}$ \\
\hline & \multirow[t]{3}{*}{ Poor-grade SAH } & $\begin{array}{l}\text { Low } \mathrm{PtiO}_{2} \text { values associated with increased mortality, but the } \\
\text { relationship with morbidity is less clear [51] }\end{array}$ & Prospective observational \\
\hline & & $\begin{array}{l}\mathrm{PtiO}_{2} \text {-derived ORx autoregulation assessment can predict the risk of } \\
\text { DCI [13] and unfavorable outcome [52] }\end{array}$ & Prospective observational \\
\hline & & $\begin{array}{l}\text { Response to } \mathrm{PtiO}_{2} \text { guided therapy associated with improved long-term } \\
\text { functional outcomes [19] }\end{array}$ & $\begin{array}{l}\text { Retrospective analysis of } \\
\text { prospective observational data }\end{array}$ \\
\hline & \multirow[t]{2}{*}{$\mathrm{ICH}$} & $\mathrm{PtiO}_{2}$ monitoring may help identify optimal CPP targets [53] & Retrospective \\
\hline & & $\begin{array}{l}\text { Reduced peri-hematomal } \mathrm{PtiO}_{2} \text { values associated with poor outcome } \\
\text { [53] }\end{array}$ & Retrospective \\
\hline
\end{tabular}



MCA infarction [54]

\section{Peri-operative:}

Cerebral angiography

Aneurysm surgery

AVM surgery

NIRS

\section{ICU:}

TBI

SAH
Low $\mathrm{PtiO}_{2}$ values correlated with severe intracranial angiographic arterial caliber reduction in patients with poor-grade SAH [55]

$\mathrm{PtiO}_{2}$ threshold of $15 \mathrm{mmHg}$ found to be a sensitive indicator of the likelihood of developing procedure-related ischemia [56]

Correlation observed between reduced $\mathrm{PtiO}_{2}$ values and development of a peri-probe ischemic infarction [57]

Association between increasing length of time with $\mathrm{rScO}_{2} \leq 60 \%$ and mortality, intracranial hypertension and compromised CPP [58]

Time-resolved NIRS was able to predict angiographic-proven vasospasm with $100 \%$ sensitivity and $85.7 \%$ specificity, and confirm vasospasm when TCD was not diagnostic [59]

May help predict cerebral edema in patients with complete MCA infarction [33]

$\mathrm{rScO}_{2}$ predicts poor outcome during endovascular therapy for AIS

[60]
Prospective observational

Retrospective

Prospective observational

\section{Case report}

Prospective observational

Prospective observational

Prospective observational

Prospective observational 


\section{Peri-operative:}

Cardiac surgery

Carotid surgery

Head-up (beach chair) position surgery
Intraoperative cerebral desaturations may be associated with more major organ morbidity and mortality [34]

The role of intraoperative cerebral desaturations in postoperative cognitive decline is unclear $[34,35,37]$

Intraoperative cerebral desaturations may be associated with protracted ICU [34] and hospital [35] LOS, although others disagree [36]

Similar accuracy and reproducibility in the detection of cerebral ischemia compared to TCD and stump pressure [39]

Hypotension-associated decreases in $\mathrm{rScO}_{2}$ are not associated with a higher incidence of postoperative cognitive dysfunction or serum biomarkers of brain injury [61]
Randomized controlled trial

Randomized controlled trial

Randomized controlled trial

Prospective observational

Prospective observational

AIS, acute ischemic stroke; CPP, cerebral perfusion pressure; DCI, delayed cerebral ischemia; GOS, Glasgow outcome score; ICH, intracerebral

hemorrhage; ICU, Intensive Care Unit; LOS, length of stay; MCA, middle cerebral artery; NIRS, near-infrared spectroscopy; ORx, oxygen reactivity index; $\mathrm{PtiO}_{2}$, brain tissue oxygen tension; $r \mathrm{ScO}_{2}$, regional cerebral oxygen saturation; SAH, subarachnoid hemorrhage; TBI, traumatic brain injury; TCD, transcranial Doppler. 


\section{Table 3}

The main variables known to influence $\mathrm{PtiO}_{2}$ values

Systemic variables:

- Partial pressure of oxygen $\left(\mathrm{PaO}_{2}\right)$

- Partial pressure of carbon dioxide $\left(\mathrm{PaCO}_{2}\right)$

- Fraction of inspired oxygen $\left(\mathrm{FiO}_{2}\right)$

- Mean arterial blood pressure

- Cardiopulmonary function

- Hemoglobin level

Brain-specific variables:

- Cerebral perfusion pressure and intracranial pressure

- Cerebral blood flow

- Cerebral vasospasm

- Cerebral autoregulatory status

- Brain tissue gradients for oxygen diffusion

- Composition of the microvasculature around the probe and the relative dominance of arterial or venous vessels 


\section{Table 4}

Summary of studies comparing outcome following brain tissue oxygen tension-directed therapy $v s$. intracranial pressure/cerebral perfusion pressure-directed therapy in patients with severe traumatic brain injury

\begin{tabular}{|c|c|c|c|c|c|c|}
\hline Reference & Study type & $\begin{array}{l}\mathrm{PtiO}_{2-} \\
\text { guided } \\
\text { therapy, } \\
\text { n }\end{array}$ & $\begin{array}{l}\text { ICP/CPP- } \\
\text { guided } \\
\text { therapy, } n\end{array}$ & $\begin{array}{l}\mathrm{PtiO}_{2} \\
\text { threshold } \\
\text { for } \\
\text { intervention }\end{array}$ & Endpoint(s) & Principle findings \\
\hline $\begin{array}{l}\text { Stiefel et al, } 2005 \\
\text { [64] }\end{array}$ & $\begin{array}{l}\text { Retrospective } \\
\text { (historical } \\
\text { controls) }\end{array}$ & 28 & 25 & $\begin{array}{l}3.33 \mathrm{kPa} \\
(25 \mathrm{mmHg})\end{array}$ & In-hospital mortality & $\begin{array}{l}\text { Mortality rate in } \mathrm{PtiO}_{2} \text { group }(25 \%) \text { significantly } \\
\text { lower than ICP/CPP group }(44 \% ; \mathrm{p}<0.05) \text {. }\end{array}$ \\
\hline $\begin{array}{l}\text { McCarthy et al, } \\
2009 \text { [66] }\end{array}$ & Prospective & 81 & 64 & $\begin{array}{l}2.66 \mathrm{kPa} \\
(20 \mathrm{mmHg})\end{array}$ & $\begin{array}{l}\text { In-hospital mortality, } \\
\text { GOS every three }\end{array}$ & $\begin{array}{l}\text { No significant difference in mortality rates between } \\
\mathrm{PtiO}_{2} \text { group }(31 \%) \text { and ICP/CPP group }(36 \% ; \mathrm{p}=\end{array}$ \\
\hline
\end{tabular}


months post-discharge.

$\begin{array}{lllll}\begin{array}{l}\text { Narotam et al, } \\ 2009[67]\end{array} & \begin{array}{l}\text { Retrospective } \\ \text { (historical }\end{array} & & 4139 & \begin{array}{l}2.66 \mathrm{kPa} \\ (20 \mathrm{mmHg})\end{array}\end{array}$

Spiotta et al, $2010 \quad$ Retrospective 70

[68]

(historical

controls)

Green et al, $2013 \quad$ Retrospective

[69] cohort study

37

cohort study

$2.66 \mathrm{kPa}$

(20 mmHg)

In-hospital mortality,

GOS and FIM at

discharge
0.52). A non-significant trend towards improved outcome (GOS 4 or 5) in $\mathrm{PtiO}_{2}$ group (79\%) compared to ICP/CPP group $(61 \% ; \mathrm{p}=0.09)$.

Higher mean GOS score in $\mathrm{PtiO}_{2}$ group (3.55 \pm $1.75)$ compared to ICP/CPP group $(2.71 \pm 1.65$; p $<0.01)$. OR for good outcome in $\mathrm{PtiO}_{2}$ group = $2.09(95 \% \mathrm{CI}=1.03$ - 4.24). Reduced mortality rate in the $\mathrm{PtiO}_{2}$ group (26\% versus $41.5 \%$; RR reduction 37\%) despite higher ISS scores in $\mathrm{PtiO}_{2}$ group.

Mortality rates significantly lower in $\mathrm{PtiO}_{2}$ group $(26 \%)$ than ICP/CPP group $(45 \%$; $\mathrm{p}<0.05)$. A

favorable outcome (GOS score of 4 or 5 ) was also observed more commonly in the $\mathrm{PtiO}_{2}$ group $(64 \%$ vs. $40 \% ; \mathrm{p}=0.01)$.

No survival difference offered by $\mathrm{PtiO}_{2}$-guided therapy $(64.9 \%$ vs. $54.1 \%, \mathrm{p}=0.34)$, or difference in discharge GCS or FIM. Of note, the $\mathrm{PtiO}_{2}-$ guided therapy group had significantly lower ISS at baseline.

Shutter et al. Prospective 53 57 2014 [20]
$2.66 \mathrm{kPa}$ (20 $\mathrm{mmHg}$ )
Proportion of time $\mathrm{PtiO}_{2}$ $<20 \mathrm{mmHg}$, safety, feasibility of protocol implementation, nonfutility (mortality, GOS-extended at 6
Median proportion of time with $\mathrm{PtiO}_{2}<20 \mathrm{mmHg}$ significantly lower in the ICP/ $\mathrm{PtiO}_{2}$ group (0.14) compared to the ICP group $(0.44, \mathrm{p}<0.00001)$. No significant difference between adverse events, and protocol violations were infrequent. Lower overall mortality and poor outcome on the 6-month GOS- 
months)

extended in the $\mathrm{ICP} / \mathrm{PtiO}_{2}$ group, but neither reached statistical significance $(\mathrm{p}=0.229$ and $\mathrm{p}=0.221$, respectively).

CI, confidence interval; CPP, cerebral perfusion pressure; FIM, functional independence measure; GCS, Glasgow Coma Scale; GOS, Glasgow Outcome Score; ICP, intracranial pressure; ISS, injury severity score; LOS, length of stay; MAP, mean arterial pressure; OR, odds ratio; PtiO ${ }_{2}$, brain tissue oxygen tension; $R C T$, randomized controlled trial; $R R$, relative risk. 


\section{Table 5}

Summary of the randomized studies evaluating outcomes following near-infrared spectroscopy-guided management of cerebral desaturations

\begin{tabular}{|c|c|c|c|c|c|c|}
\hline Reference & $\begin{array}{l}\text { Surgery } \\
\text { type }\end{array}$ & $\begin{array}{l}\text { Intervention } \\
\text { arm, } \mathbf{n}\end{array}$ & $\begin{array}{l}\text { Control } \\
\text { arm, n }\end{array}$ & $\begin{array}{l}\text { Target } \mathrm{rScO}_{2} \\
\text { values in } \\
\text { intervention arm }\end{array}$ & Endpoint(s) & Principle findings \\
\hline $\begin{array}{l}\text { Murkin et al. } 2007 \\
\text { [34] }\end{array}$ & $\mathrm{CABG}$ & 100 & 100 & $\begin{array}{l}\geq 75 \% \text { of baseline } \\
\text { threshold }\end{array}$ & $\begin{array}{l}30 \text { day postoperative } \\
\text { morbidity and } \\
\text { mortality }\end{array}$ & $\begin{array}{l}\text { Prolonged cerebral desaturations }(\mathrm{p}=0.014) \\
\text { and ICU stay observed in the control group } \\
(\mathrm{p}=0.029) . \mathrm{MOMM}^{*} \text { higher in the control } \\
\text { group }(\mathrm{p}=0.048) \text { and associated with lower } \\
\text { baseline and mean } \mathrm{rScO}_{2} \text {, more cerebral } \\
\text { desaturations, longer } \mathrm{ICU} \text { and hospital LOS. }\end{array}$ \\
\hline Slater et al. 2009 [35] & CABG & 125 & 115 & $\begin{array}{l}\geq 80 \% \text { of baseline } \\
\text { threshold }\end{array}$ & $\begin{array}{l}\text { Cognitive function } \\
\text { (using a battery of } \\
\text { tests) up to } 3 \text { months } \\
\text { and hospital LOS }\end{array}$ & $\begin{array}{l}\text { A high } \mathrm{rScO}_{2} \text { desaturation score ( }>3000 \% \text { - } \\
\text { second) associated with early postoperative } \\
\text { cognitive decline }(\mathrm{p}=0.024) \text { and hospital } \\
\text { stay }>6 \text { days }(\mathrm{p}=0.007) \text {. Benefits of the } \\
\text { intervention on cognitive outcomes lost in } \\
\text { multivariate analysis. }\end{array}$ \\
\hline $\begin{array}{l}\text { Deschamps et al. } \\
2013 \text { [36] }\end{array}$ & $\begin{array}{l}\text { High-risk } \\
\text { cardiac } \\
\text { surgery** }\end{array}$ & 23 & 25 & $\begin{array}{l}\geq 80 \% \text { of baseline } \\
\text { threshold for } 15 \\
\text { seconds }\end{array}$ & $\begin{array}{l}\text { Desaturation load (\% } \\
\text { desaturation } x \text { time), } \\
\text { ICU and hospital } \\
\text { LOS }\end{array}$ & $\begin{array}{l}\text { Half of the patients had cerebral } \\
\text { desaturations that could be reversed } 88 \% \text { of } \\
\text { the time. Interventions resulted in smaller } \\
\text { desaturation loads in the operating room and } \\
\text { ICU. No difference in hospital or ICU LOS. }\end{array}$ \\
\hline
\end{tabular}

* Major organ morbidity and mortality (MOMM) composed of the following variables as determined by the Society of Thoracic Surgeons: death, stroke, reoperation for bleeding, mediastinitis, surgical reintervention, renal failure requiring dialysis, and ventilation time $>48 \mathrm{~h}$.

** Desaturation score calculated by multiplying $\mathrm{rScO}_{2}$ less than $50 \%$ by duration in seconds, 
** High-risk cardiac surgery defined by the authors as: redo surgery, adult congenital surgery, thoracic aortic surgery with and without circulatory arrest, and combined procedures surgery.

$C A B G$, coronary artery bypass grafting; ICU, intensive care unit; $L O S$, length of stay; $\mathrm{OR}$, odds ratio; $r \mathrm{ScO} \mathrm{O}_{2}$, regional cerebral oxygen saturation. 